Lecture Notes in Computer Science

Edited by G. Goos, J. Hartmanis, and J. van Leeuwen 
Springer

Berlin

Heidelberg

New York

Hong Kong

London

Milan

Paris

Tokyo 
Dimitri Konstantas Michel Leonard Yves Pigneur Shusma Patel (Eds.)

\section{Object-Oriented Information Systems}

9th International Conference, OOIS 2003

Geneva, Switzerland, September 2-5, 2003

Proceedings 


\section{Volume Editors}

\section{Dimitri Konstantas}

University of Geneva

Department of Information Systems, 1211 Geneva 4, Switzerland

E-mail: Dimitri.Konstantas@unige.ch

and

University of Twente

Department of Computer Science, P.O.Box 217, 7500 Enschede, The Netherlands

E-mail: Dimitri.Konstantas@utwente.nl

Michel Leonard

University of Geneva

Department of Information Systems, 1211 Geneva 4, Switzerland

E-mail: Michel.Leonard@unige.ch

\section{Yves Pigneur}

University of Lausanne

Ecole des Hautes Etudes Commerciales, 1015 Dorigny, Switzerland

E-mail: yves.pigneur@hec.unil.ch

\section{Shusma Patel}

South Bank University

School of Computing, Information Systems and Mathematics

103 Borough Road, London SE1 0AA, UK

E-mail:shusma@sbu.ac.uk

\section{Cataloging-in-Publication Data applied for}

A catalog record for this book is available from the Library of Congress.

Bibliographic information published by Die Deutsche Bibliothek

Die Deutsche Bibliothek lists this publication in the Deutsche Nationalbibliografie; detailed bibliographic data is available in the Internet at $<\mathrm{http}: / /$ dnb.ddb.de $>$.

CR Subject Classification (1998): H.2, H.3, H.4, H.5, I.2, D. 2, D.4, K.4.4, J.1

ISSN 0302-9743

ISBN 3-540-40860-6 Springer-Verlag Berlin Heidelberg New York

This work is subject to copyright. All rights are reserved, whether the whole or part of the material is concerned, specifically the rights of translation, reprinting, re-use of illustrations, recitation, broadcasting, reproduction on microfilms or in any other way, and storage in data banks. Duplication of this publication or parts thereof is permitted only under the provisions of the German Copyright Law of September 9, 1965, in its current version, and permission for use must always be obtained from Springer-Verlag. Violations are liable for prosecution under the German Copyright Law.

Springer-Verlag Berlin Heidelberg New York

a member of BertelsmannSpringer Science+Business Media GmbH

http://www.springer.de

(C) Springer-Verlag Berlin Heidelberg 2003

Printed in Germany

Typesetting: Camera-ready by author, data conversion by PTP-Berlin $\mathrm{GmbH}$

$\begin{array}{lll}\text { Printed on acid-free paper } & \text { SPIN: } 10950043 \quad 06 / 3142 & 543210\end{array}$ 


\section{Preface}

The conference on Object Oriented Information Systems (OOIS) is now an established international conference where innovative ideas, research, applications, and experiences in the design, development, and use of object oriented information systems, from both the academic and industrial environments, are presented.

The ninth OOIS conference was held at the University of Geneva, September 2-5, 2003. The main theme was the Evolution of Object Oriented Information Systems. The papers presented ideas and issues related to the evolution, adaptability, restructuring, and flexibility of OOIS. In the context of the conference, five workshops and four tutorials were organized providing a discussion forum for new ideas and including in depth presentations on important "hot" subjects.

The three invited speakers of the ninth OOIS conference provided an alternative view on OOIS and their evolution. Prof. John Mylopoulos (University of Toronto and VLDB president) gave the opening presentation entitled "Agent Oriented IS Development", Dr. Richard Soley (OMG President and CEO) gave the closing presentation entitled "Model Driven Architecture: The Evolution of Object-Oriented Systems?" and Prof. Lina Al-Jadir (American University of Beirut) gave the theme presentation entitled "Once Upon a Time a DTD Evolved into Another DTD...".

The conference attracted 80 papers from 45 countries and the program committee accepted 29 full papers and 11 short papers. The selected papers were categorized in eight themes, namely

- Evolution of OOIS

- OOIS Frameworks

- Patterns and Components

- Object Oriented Data Bases

- XML and Web

- Modeling of IS and

- OO Design and Architecture

We would like to thank the program committee members and the referees who reviewed the submitted papers as well as the local organization committees and institutions for all the effort and support in setting up and organizing the conference. Last but most important we would like to thank the authors and the invited speakers that really made the conference happen!

June 2003

Dimitri Konstantas

Michel Leonard Yves Pigneur Shusma Patel 


\section{Organization}

\section{General Chair}

Michel Leonard (University of Geneva, Switzerland)

\section{Program Co-chairs}

Dimitri Konstanas (University of Geneva, Switzerland/Univ. of Twente, The Netherlands)

Yves Pigneur (University of Lausanne, Switzerland)

Shushma Patel (South Bank University, UK)

\section{Program Committee}

Lina Al-Jadir (American University of Beirut, Libanon)

Lora Aroyo (University of Eindhoven, The Netherlands)

Daniel Bardou (IMAG-LSR, France)

Franck Barbier (University of Pau, France)

Zohra Bellahsene (LIRMM, France)

Bert-Jan van Beijnum (University of Twente, The Netherlands)

Ciaran Bryce (University of Geneva, Switzerland)

Jean-Louis Cavarero (University of Nice, France)

Islam Choudhury (London Guildhall University, UK)

Sergio de Cesare (Brunel University, UK)

Johan Eder (University of Klagenfurt, Austria)

Jean-Luc Hainaut (University of Namur, Belgium)

Brian Henderson-Sellers (University of Technology of Sydney, Australia)

Marianne Huchard (University of Montpellier-LIRMM, France)

Gerti Kappel (Technical University of Vienna, Austria)

Axel Klostermayer (University of Magdeburg, Germany)

Diamantis Koumpis (Altec S.A., Greece)

Zoe Lacroix (Arizona State University, USA)

Periklis Mitkas (Aristotle University of Thessaloniki, Greece)

John Mylopoulos (University of Toronto, Canada)

Moira Norrie (ETHZ, Switzerland)

Maria Orlowska (University of Queensland, Australia)

Vaggelis Ouzounis (Commission of the European Union)

George Papadopoulos (University of Cyprus, Cyprus)

Mike Papazoglou (Tilburg University, The Netherlands)

Dilip Patel (South Bank University, UK) 
Jolita Ralyte (University of Geneva, Switzerland)

D Janaki Ram (Indian Institute of Technology, India)

Antoni Olive Ramon (Technical University of Catalonia, Spain)

Dominque Rieu (University Pierre Mendès, France)

Colette Rolland (University of Paris-Sorbonne, France)

Michael Rys (Microsoft Research, USA)

José Samos (University of Granada, Spain)

Keng Siau (University of Nebraska-Lincoln, USA)

Roberto Zicari (Johann Wolfgang Geothe University of Frankfurt, Germany)

\section{Workshop Chair}

Jolita Ralyte (University of Geneva, Switzerland)

\section{Tutorials Chair}

Thibault Estier (University of Lausanne, Switzerland)

\section{Local Organization}

Manuel Oriol (University of Geneva, Switzerland)

Mehdi Snene (University of Geneva, Switzerland)

Slim Turki (University of Geneva, Switzerland)

Michel Pawlak (University of Geneva, Switzerland)

\section{External Referees}

Claus Priese (Johann Wolfgang Geothe University of Frankfurt, Germany) Majid Nabavi (University of Nebraska-Lincoln, USA) 


\section{Table of Contents}

\section{Invited Talks}

Agent Oriented Software Development ................... 1

John Mylopoulos

Model Driven Architecture: The Evolution of

Object-Oriented Systems?....................... 2

Richard Mark Soley

Once Upon a Time a DTD Evolved into Another DTD............. 3

Lina Al-Jadir, Fatmé El-Moukaddem

\section{Evolution of OOIS}

Evolution of Collective Object Behavior in Presence of

Simultaneous Client-Specific Views . . . . . . . . . . . . . . . 18

Bo Nørregaard Jørgensen, Eddy Truyen

Evolving Derived Entity Types in Conceptual Schemas in the UML . . . . 33

Cristina Gómez, Antoni Olivé

Object-Oriented Graceful Evolution Monitors.................. 46

Vic Page, Maurice Dixon, Peter Bielkowicz

Stepwise and Rigorous Development of Evolving Concurrent

Information Systems: From Semi-formal Objects to Sound

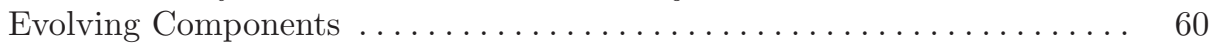

Nasreddine Aoumeur, Gunter Saake

Compliance Gaps: A Requirements Elicitation Approach in the

Context of System Evolution

Camille Salinesi, Anne Etien

UML-Based Metamodeling for Information System Engineering

and Evolution ..................................

Marie-Noëlle Terrasse, Marinette Savonnet, George Becker, Eric Leclercq

\section{OOIS Frameworks}

Building a Wizard for Framework Instantiation Based on a

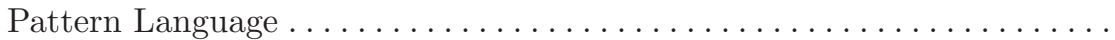

Rosana T.V. Braga, Paulo Cesar Masiero 
Event-Based Software Architectures . . . . . . . . . . . . . . . . . . 107

Monique Snoeck, Wilfried Lemahieu, Cindy Michiels, Guido Dedene

Aided Domain Frameworks Construction and Evolution............ 118

Félix Prieto, Yania Crespo, José M. Marqués, Miguel A. Laguna

\section{Patterns and Components}

A Contract-Based Approach of Resource Management in

Information Systems

Nicolas Le Sommer

Representing User-Interface Patterns in UML

Nuno Jardim Nunes

Accommodating Changing Requirements with EJB

Bart Du Bois, Serge Demeyer

A Framework for Supporting Views in Component Oriented

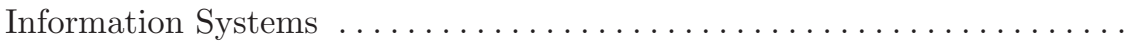

O. Caron, B. Carré, A. Muller, G. Vanwormhoudt

Enabling Design Evolution in Software through Pattern

Oriented Approach .......................................... 179

D. Janaki Ram, M.S. Rajasree

Extracting Domain-Specific and Domain-Neutral Patterns Using

Software Stability Concepts ............................. 191

Haitham Hamza, Ahmed Mahdy, Mohamed E. Fayad, Marshall Cline

\section{Object Oriented Data Bases}

Designing Storage Structures for Management of Materialised

Methods in Object-Oriented Databases ....................... 202

Juliusz Jezierski, Mariusz Masewicz, Robert Wrembel, Bogdan Czejdo

Overcoming the Complexity of Object-Oriented DBMS

Metadata Management .................................... 214

Piotr Habela, Kazimierz Subieta

Primitive Operations for Schema Evolution in ODMG Databases....... 226

Cecilia Delgado, José Samos, Manuel Torres

\section{XML and Web}

Models and Guidelines for the Design of Progressive Access in

Web-Based Information Systems ........................ 238

Marlène Villanova-Oliver, Jérôme Gensel, Hervé Martin 
Mediaviews: A Layered View Mechanism for Integrating

Multimedia Data

Hyon Hee Kim and Seung Soo Park

An Efficient Object Hierarchy Construction for Viewing Internet

Products on Mobile Phones ......................

Sangho Ha, Jungik Choi, In-Gook Chun

\section{Evolution}

A Conceptualization of OO Evolution

Dalila Tamzalit, Mourad Oussalah

Workflow Evolution: Generation of Hybrid Flows

Johann Eder, Michael Saringer

Supporting Database Evolution: Using Ontologies Matching

Nadira Lammari, Jacky Akoka, Isabelle Comyn-Wattiau

Designing Evolvable Location Models for Ubiquitous Applications

Silvia Gordillo, Javier Bazzocco, Gustavo Rossi, Robert Laurini

Refactoring the Scenario Specification: A Message Sequence

Chart Approach . . .........................

Shengbing Ren, Kexing Rui, Greg Butler

\section{OO Design and Architecture}

Model Driven Architecture for Agile Web Information

System Engineering . . . . . . . . . . . . . . . . . . . . . . . . . . 299

William El Kaim, Philippe Studer, Pierre-Alain Muller

DSL-DIA - An Environment for Domain-Specific Languages for

Database-Intensive Applications

Jernej Kovse, Theo Härder

An Object-Oriented Framework for Managing Cooperating

Legacy Databases.

H. Balsters, E.O de Brock

Object-Oriented Component Identification Method Using the

Affinity Analysis Technique

Yoon-Jung Jang, Eun-Young Kim, Kyung-Whan Lee

Distributed Information System Design Based on Integrity

Constraints Optimization: The FKDO Algorithm

Snene Mehdi, Pardellas Jorge

Object-Oriented Design of RTI Using Design Patterns

Tae-Dong Lee, Jung-Hun Jin, Chang-Sung Jeong 


\section{Modelling of IS}

Functional Size Measurement of Multi-layer Object-Oriented

Conceptual Models .

Geert Poels

RISA: Object-Oriented Modeling and Simulation of

Real-Time Distributed System for Air Defense . . . . . . . . . . . . . . . 346

Tae-Dong Lee, Bom-Jae Jeon, Chang-Sung Jeong, Sang-Yong Choi

Software Process and Reuse: A Required Unification. . . . . . . . . . . . 356

Miguel A. Laguna, Bruno González-Baixauli, Oscar López,

Francisco J. García

Distributed Systems Development: Can We Enhance Evolution by

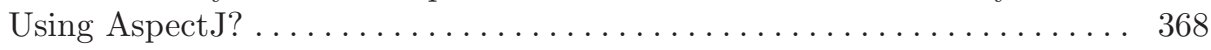

Cormac Driver, Siobhán Clarke

Conciliating User Interface and Business Domain Analysis and Design . . 383 Isabelle Mirbel, Violaine de Rivieres

Atomic Use Case: A Concept for Precise Modelling of

Object-Oriented Information Systems. . . . . . . . . . . . . . . . . 400 Kinh Nguyen, Tharam Dillon

An Approach of Model Transformation Based on Attribute Grammars . . 412 May Dehayni, Louis Féraud 